\title{
HEALTH LITERACY OF A SAMPLE OF PORTUGUESE ELDERLY
}

\section{VEIGA Sofia, SERRÃO Carla}

School of Education of the Porto Polytechnic Institute, Porto, Portugal

\begin{abstract}
This article presents the results of a study developed within the scope of the Project Health Literacy: a challenge in and for the elderly, funded by the Calouste Gulbenkian Foundation. It tried to evaluate the metric qualities of the Newest Vital Sign Test (NVS, Copyright $($ C Pfizer Inc.) applied to elderly; evaluate the degree of health literacy of a sample of elderly Portuguese people; get to know the association between the degree of health literacy and some sociodemographic features, the general health state, and quality of life. It was conducted a quantitative study with 433 adults over 65 years of age, mostly female, and with heterogeneous levels of education. The instrument used was a battery of tests in order to assess the degree of health literacy (Newest Vital Sign), and the quality of life (WHOQOL). The NVS proved to be a reliable and sensitive to changes due to various demographic characteristics instrument. The results indicate that the majority of the participants (80\%) showed a level of low health literacy, meaning that only $20 \%$ of respondents will be able to interpret and use effectively information related with health. Gender, educational attainment, age and marital status, as well as the perception of the elderly on their general health state and quality of life, proved to be variables that affect significantly the level of health literacy of participants. These results point to the urgent need to enhance health literacy in the elderly population, in general, and among the most vulnerable groups, in particular.
\end{abstract}

Keywords: Elderly; Health Literacy; Quality of Life; Sociodemographic Variables.

\section{Background}

The demographic ageing has been increasing in the Western Europe countries, estimating that by 2060 the number of people aged 65 or more will be three times the number of young people. This framework is due mostly to the increase in life expectancy, decrease in mortality and reduced existing fertility, and already shows significant social, economic and cultural impacts (Rosa, 2012). In the Portuguese reality, according to data from the National Institute of Statistics (2012), the population age-group structure in 2011 stressed the imbalances already evinced in the previous decade. The bottom of the pyramid has diminished, corresponding to the younger population and the top has extended, corresponding to the increase of the elderly. It is also possible to verify that, in the last decade, there has been an increase of $26 \%$ of individuals aged above 69 , being that value likely to rise 
up to $40.4 \%$ till 2050 , moving from eighth to second place regarding to elderly population, among 195 countries. Nevertheless, population ageing brings new and important challenges, some common to the various European realities, and some specific to each reality and particular individual. As referred by Carvalho and Dias (2011), human ageing involves aspects of sociocultural, political and economic nature that are found in dynamic interaction and that are in permanent connection with the biological and subjective dimension of the individuals. Thereby, the ageing process does not occur identically in everyone and in all realities as it depends on a set of factors, one of which being the way societies face this phenomenon, as well as how the individual envisions its own ageing.

One of the biggest current concerns is the encouragement of active ageing, as this is related to the increase of healthy life and the increase of people's quality of life during the ageing process. There really is a political structure destined exclusively to active ageing. The World Health Organization states that this requires actions at three keystones levels: health, participation and security. At the health level it is indispensable that people have access to every health care that they need and that behaviour and environment risk factors stay low. As to participation, it is essential that people continue to get involved in activities in which they can still contribute to society. Lastly, at the security level, protection services should be provided to elderly taking into consideration their various needs (WHO, 2002). This way the conditions to a good quality of life are guaranteed.

Being quality in health crucial in an elderly quality of life, it is then realized the importance of promoting one of its domains, the health literacy. This is established by WHO as a set of "cognitive and social skills which determine the motivation and ability of individuals to gain access to, understand and use information in ways which promote and maintain good health. It entails the acquisition of knowledge, personal skills and confidence to act in a healthy way, through changes of style and life conditions" (WHO, 1998, p. 10).

Health literacy is a key component so that individuals can have an effective participation in the decision-making process, which requires knowledge and skills to learn new information, think critically on how information applies to personal circumstances, navigate the health system and interact with the distinctive health professionals (e. g., Toçiet al., 2013). Nevertheless, the diverse national and international studies done have shown low health literacy on behalf of general population and the elderly in particular, with negative consequences to health state and their quality of life (e. g., Liu et al., 2015; Manafo, \& Wong, 2012; Reisiet al., 2014; Wagner et al., 2007). Among other aspects, it is to be noted that these people present, in general, difficulties in accessing the health system, in understanding information and suggested treatments, as well as following the instructions of the health professionals (e. g., Baker et al., 1996; Barrett \& Puryear, 2006; Cho et al., 2008; Davis et al., 2006). Other studies have shown that people that could benefit the most from health care providers' service and from the potential protective effect of health literacy, such as chronic sick people, are the ones to 
DOI: $10.1515 /$ arhss-2016-0003

Applied Research In Health And Social Sciences: Interface And Interaction, Vol. 13, No. 1, 2016

display the lowest degree of health literacy (e. g., Speros, 2005; Kim, 2009; Santos, 2010). This comes up linked to a worse general health state, both physical and mental (e. g., Speros, 2005; Kim, 2009; Osborn et al., 2011), as well as to a lower level of autonomy and empowering of the subjects (Nutbeam, 2000). An inadequate level of health literacy has significant implications on health results, on the usage of health services, and, therefore, in health expenses (Weiss \& Palmer, 2004).

Concerning some demographic variables, the diverse studies concluded that health literacy was notably lower among older people (e. g., Baker et al., 2000; Cho et al., 2008; Wagner et al., 2007) and less educated (e. g., Bennett et al., 2009; Liu et al., 2015). However, concerning gender, there is no agreement in the obtained results in different researches, some showing that men present higher health literacy (e. g., Jovic-Vranes et al., 2009; Lee et al., 2010; Reisi et al., 2014; Toçi et al., 2013), meanwhile others show the opposite (Sudore et al., 2006; Wagner et al., 2007). Finally, concerning the variable of marital status, married individuals present a higher level of health literacy (e. g., Reisi et al., 2014). Taking into account this framework, was developed the Health Literacy Project: a challenge in and to the elderly. It was coordinated by the School of Education, along with the School of Health Technologies of the Porto Polytechnic Institute, and funded by the Calouste Gulbenkian Foundation under the scope of the Gulbenkian Programme for Innovation in Health. Two studies on the thematic of health literacy were developed within this Project. The first, of quantitative nature, intended to: a) assess the metric qualities of the Newest Vital Sign Test (NVS, Copyright (C) Pfizer Inc.) applied to elderly; b) assess the degree of health literacy of a sample of elderly people; c) get to know the link connection between the degree of health literacy, the general health state and the sociodemographic features of the participants. The second, of qualitative nature, aimed to determine the representations, perceptions and institutional practices and professionals of a set of health professionals and of psychosocial intervention in the health literacy domain.

\section{Methodology}

\section{Sample}

The sample of the study integrated 433 Caucasian subjects, between 65 and 97 years of age (M=76 years old; $\mathrm{DP}=7.30$ ), being $66 \%$ of the subjects female and $34 \%$ male, from the district of Porto, Portugal. The majority is married (42\%), being the remaining widowers (38\%). Concerning academic qualifications, the majority of the subjects has, at the most, the 4th year of schooling (55\%). Nevertheless, a considerable percentage of participants with higher education (23\%) is noted. The occupations of the subjects previous to their retirement were quite diverse, including senior officials, technicians and professionals, as well as unskilled workers. 


\section{Methods}

The application of the test battery was done individually, being possible in three different manners: self-administered, in which, after reading the instructions, the participant reads and fills in the questionnaire without any help ( $\mathrm{n}=198 ; 46.2 \%)$; assisted by the observer, who read the instructions and explained how to fill in the questionnaire, but the elderly subject was the one to read the questions and mark the answers $(\mathrm{n}=26 ; 6.1 \%)$; administered by the observer, who read the instructions, the questions and ticked the answers given by the participant ( $\mathrm{n}=205 ; 47.8 \%)$.

\section{Tool}

The participants answered to the Newest Vital Sign (NVS), developed by Weiss and colleagues (2005), that assesses the degree of health literacy. Along with NVS, it was also used the WHOQOLbref - Abbreviated Instrument of Quality Life Assessment of World Health Organization, developed by a working group of the World Health Organization in 1994 (World Health Organization Quality of Life Group - WHOQOL Group, 1994).

Metric qualities of Newest Vital Sign (Copyright (C) Pfizer Inc.). The reliability of the used instrument, ascertained by the analyses of internal consistency, shows similar results to the ones found by the authors of the original scale $(\alpha=0,76)$ (Weiss et al., 2005). Concerning validity, it was noted that the results of the instrument varied according to the sociodemographic features, being therefore possible to conclude that this test coats itself with properties that seem to show their adequacy to assess the levels of health literacy among elderly people, given guidelines on the relevant contents to education, training and information, as pointed by Luis (2010).

\section{Ethics}

Participants gave their written consent and showed willingness to participate in this study. In this process was also safeguarded the possibility of consent be revocable at any time at the request of the respondent.

\section{Findings}

Health literacy: descriptive results. The percentage of correct answers is relatively low, ranging between $18 \%$ (item 6 ) and $31 \%$ (item 5). It should be noted that the majority of the participants chose not to answer to one or more items. The percentage of no answer ranged between $51 \%$ (item 1) and $62 \%$ (item 4). In a similar way, the average was 1.36 (DP $=1.96)$, showing that in average the participants got one in every six answers correct, despite the standard deviation value enhancing quite a lot of variability. It was also possible to determine that a high percentage of participants did not manage to answer or chose not to answer any of the questions (58\%), whereas only $7 \%$ answered 
DOI: 10.1515/arhss-2016-0003

Applied Research In Health And Social Sciences: Interface And Interaction, Vol. 13, No. 1, 2016

correctly all the questions. It is thus verifiable that there are relatively low levels of literacy among our participants.

Differences in health literacy levels according to gender. For comparison among elderly people of male and female gender, concerning intermediate levels of health literacy, $t$ tests were made to independent samples to a level of statistical significance of 5\%. Beyond statistical significance of the results obtained, we used the magnitude of the size of the reported effect. To do so, the $d$ coefficient of Cohen was calculated, which is based on the average standardized differences, being $d=.20$ considered to be a low or modest effect, $d=.50$ a moderate effect and $d=.80$ an important effect (Cohen, 1992). The obtained results can be reviewed in Table 1.

Table 1

$t$ tests for comparison of the obtained results regarding health literacy levels in both genders

\begin{tabular}{|c|c|c|c|c|c|c|c|c|c|}
\hline & \multirow[b]{3}{*}{$N$} & \multirow{2}{*}{\multicolumn{2}{|c|}{$\begin{array}{c}\text { Sex } \\
\text { Male }\end{array}$}} & \multirow{2}{*}{\multicolumn{2}{|c|}{$\begin{array}{c}\text { Sex } \\
\text { Female }\end{array}$}} & \multirow[b]{3}{*}{$t$} & \multirow[b]{3}{*}{$g l$} & \multirow[b]{3}{*}{$p$} & \multirow[b]{3}{*}{$d$} \\
\hline & & & & & & & & & \\
\hline & & $M$ & $D P$ & $M$ & $D P$ & & & & \\
\hline \multicolumn{10}{|l|}{ NVS } \\
\hline Health Literacy (total) & 433 & 1.66 & 2.06 & 1.21 & 1.91 & 2.18 & 277.09 & 030 & 0.71 \\
\hline Health in Literacy* & 182 & 3.31 & 1.74 & 3.19 & 1.79 & 0.44 & 180 & 664 & 0.18 \\
\hline
\end{tabular}

Concerning intermediate levels of health literacy, it turns out that the male gender participants obtained higher average scores than the feminine gender participants, $t(277.09)=2.18, p<.05$. This difference was considered to be statistically significant and the value of the $d$ coefficient of Cohen of .17 indicates a low effect. These differences disappear, though, when we excluded the subjects with complete failure in the test, who represented $58 \%$ of the sample.

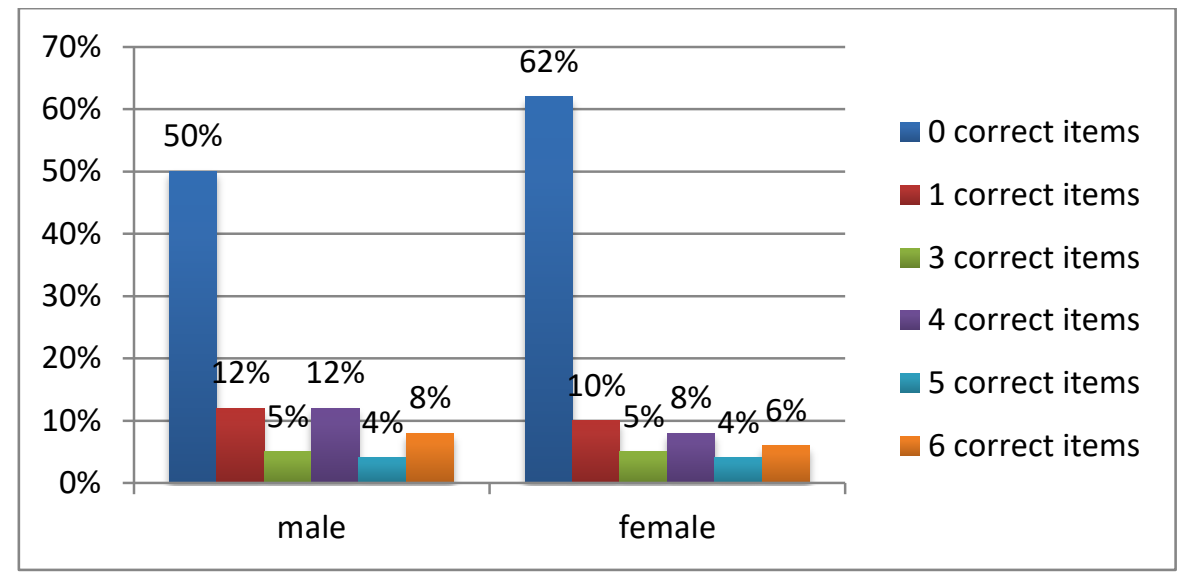

Figure 1. Percentage of participants according to the number of correct answers in Newest Vital Sign relatively to gender $(N=433)$ 
To the 108 subjects of the feminine gender and 74 of the masculine gender that have at least one success in the test, the average is close to the average value of 3, respectively, 3.19 and 3.31, not being the difference considered statistically significant, $t(180)=0.44, n s$. As a matter of fact, the differences at gender level seem to reside in the proportion of men and women with complete failure in the test: $50 \%$ in the first and $62 \%$ in the second (see Figure 1). A chi-squared test seems to indicate that these proportions are statistically significant, $\chi 2(1)=5.86, p=.016$, wherefore it is possible to infer that women have higher probability of not answering correctly any item on the test (see Figure 1).

Associations between the levels of health literacy and age. In order to get to know the association between the levels of health literacy and age, the correlation of Pearson was calculated to a level of statistical significance of $5 \%$. The coefficient of correlation was regarded in terms of size of effect, according to Cohen' conventions (1992): a $r$ of .10 is considered low (weak association), a $r$ of .30 is considered intermediate (moderate association) and a $r$ of .50 is considered high (strong association). The association found was negative, average $r=-.34$, which indicates that the values of both variables tend to vary in reverse, which means, the levels of literacy tends to be lower with the advancement of age.

Differences in health literacy levels according to level of schooling. With the aim of examining the effect of the level of schooling of the respondents in the health literacy levels, having verified that the data did not meet the demanded requirements by the variance analysis, namely concerning homogeneity of variance, the non-parametric analyses the Kruskal-Wallis test was used, at a level of statistical significance of .05 . To identify the specific differences between the groups, we conducted Mann-Whitney tests, at a level of statistical significance .0083, after Bonferroni correction. We have used the four levels created to describe the scholarship of the respondents (level $1=$ until 4 th grade; level 2 = between the 5 th and the 9th grade; level $3=$ high school and level $4=$ higher education). The obtained results can be reviewed in Table 2 .

Table 2

Comparison of the obtained results in the Newest Vital Sign according to the level of scholarship

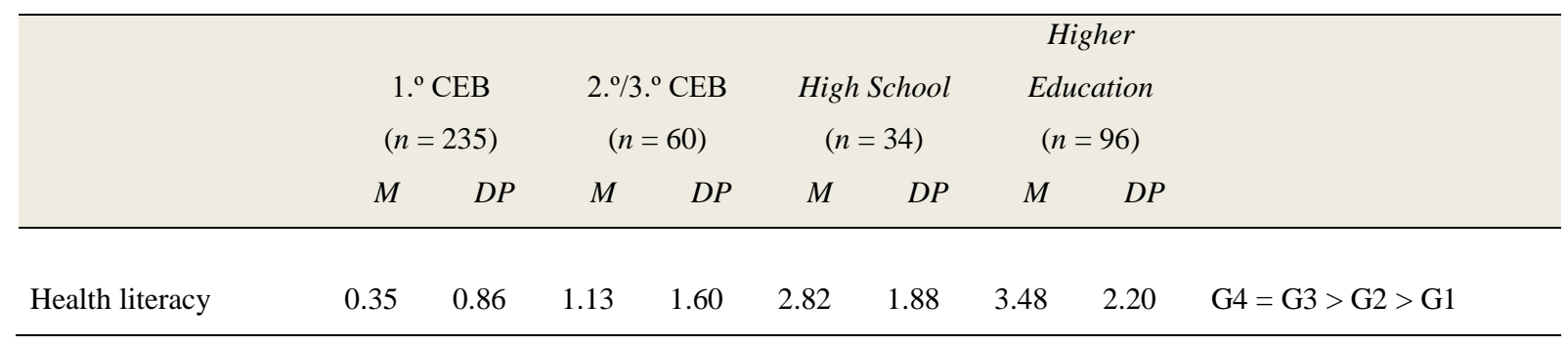

It is possible to note that a statistically significant effect has been found, indicting the existence of differences among the several groups of subjects, $H(3)=175.22, p<.001$. The Mann-Whitney analyses have allowed to verify that the subjects with $1 .{ }^{\circ} \mathrm{CEB}$ (until 4th grade) present lower results than every other group, $U=5171.50$, $p<.001, U=1184.00, p<.001, U=2864.50, p<.001$. In the same way, the subjects with 2nd or 3rd CEB 
DOI: 10.1515/arhss-2016-0003

Applied Research In Health And Social Sciences: Interface And Interaction, Vol. 13, No. 1, 2016

presented lower results than the groups of subjects with secondary school and higher education, respectively, $U$ $=520.00, p<.001$ e $U=1212.50, p<.001$. No differences have been noticed regarding the average of the subjects with secondary school and higher education, $\mathrm{U}=1292.50, p=.067$. Therefore, and as expected, it is noted that the level of scholarship has a determinant role in the average levels of health literacy. So as to know the size of the effect of the scholarship level, it was made the calculation of the correlation of Pearson between the scholarship level and the health literacy levels, to a level of statistical significance of $5 \%$. The correlation .67 indicates a strong association.

Differences in health literacy levels according to marital status. So as to analyse the effect of marital status in the health literacy levels, differences between married subjects $(n=185)$ and widowers $(n=166)$ were taken into consideration. Elderly who were single $(n=37)$, non-marital partnership $(n=7)$, separated $(\mathrm{n}=8)$ and divorced $(n=29)$, were excluded of the analyses due to the reduced number in which they appeared in this sample. $t$ tests to independent samples were made to a level of statistical significance of $5 \%$. The obtained results can be reviewed in Table 3 .

Table 3

$\mathrm{t}$ tests for comparison of the obtained results regarding health literacy levels according to marital status

\begin{tabular}{|c|c|c|c|c|c|c|c|c|}
\hline & & & & & & & & \\
\hline & $M$ & $D P$ & $M$ & $D P$ & $t$ & $g l$ & $p$ & $d$ \\
\hline Health literacy & 1.98 & 2.21 & 0.70 & 1.43 & 6.49 & 319.3 & 000 & 0.51 \\
\hline
\end{tabular}

Married subjects tend to obtain higher average values of health literacy than widowers, $t(319.3)=$ $6.49, p<.05$. The value of the $d$ coefficient of Cohen of 0.68 indicates a moderate effect. However, the groups also differ relatively to age, presenting the widowers' group an higher average of age $M=$ 79.86, $D P=6.23$, when compared to married subjects, $M=73.77, D P=6.80, t(349)=-8.74, p<.05$. Therefore, we proceeded once more to the comparison between both groups, controlling age. The results showed that the differences between both groups still existed, even when age was controlled, $F$ $(1,348)=16.30, p<.05$. Therefore, the marital status seems to play a relevant role in the levels of health literacy among the subjects of these two groups.

Degree of health literacy and general disease. Concerning the presence of disease, as can be seen from Table 4, it is noted that the participants who refer having some sort of disease obtained lower average score than the participants who claim not having any kind of disease, $t(352.8)=-5.80$, $\mathrm{p}<$ .05. The value of the $d$ coefficient of Cohen of .57 indicates a moderate effect. Once more, these two groups differ as to age, tending the participants with some sort of disease to be older, 76.93 (DP = $7.06)$ e $74.73(\mathrm{DP}=7.36), t(428)=3.14, \mathrm{p}<.05$. Again we compared the values of health literacy, controlling age and, once more, the results showed that the differences between the groups still existed, even when age was controlled, $\mathrm{F}(1,428)=35.51, \mathrm{p}<.05$ (see Table 4$)$. 
t tests for comparison of the obtained results regarding health literacy levels according to disease status

\begin{tabular}{|c|c|c|c|c|c|c|c|c|}
\hline & \multicolumn{2}{|c|}{$\begin{array}{l}\text { With some } \\
\text { disease } \\
(n=236)\end{array}$} & \multicolumn{2}{|c|}{$\begin{array}{l}\text { Without disease } \\
\qquad(n=194)\end{array}$} & \multirow[b]{2}{*}{$t$} & \multirow[b]{2}{*}{$g l$} & \multirow[b]{2}{*}{$p$} & \multirow[b]{2}{*}{$d$} \\
\hline & $M$ & $D P$ & $M$ & $D P$ & & & & \\
\hline Health literacy & 0.87 & 1.64 & 1.97 & 2.17 & -5.80 & 352.8 & 000 & 0.57 \\
\hline
\end{tabular}

Associations between health literacy and quality of life. With the intention of evaluating quality of life, the WHOQOL-bref - Abbreviated Instrument of Quality Life Assessment of World Health Organization was used, developed by a working group of the World Health Organization in 1994 (World Health Organization Quality of Life Group - WHOQOL Group, 1994). This questionnaire integrates four domains of quality of life, specifically the Physical, Psychological, Social Relations and Environment, being also possible the calculation of a global indicator designated General Facet of Quality of Life. Regarding Quality of Life, the average values obtained varied from 69.39 (general domain) to 73.62 (social relations), what indicates moderate levels of quality of life (see Table 5).

Table 5

Results obtained in the assessment tool on life quality (WHOQOL-bref)

\begin{tabular}{|c|c|c|c|c|c|}
\hline & $N$ & $M$ & $D P$ & Min & Max \\
\hline General & 426 & 69.39 & 15.63 & 20.0 & 100 \\
\hline D1 Physical & 428 & 69.54 & 14.17 & 25.7 & 100 \\
\hline D2 Psychological & 427 & 71.29 & 14.04 & 20.0 & 100 \\
\hline D3 Social Relations & 423 & 73.62 & 11.69 & 33.3 & 100 \\
\hline D4 Environment & 427 & 70.46 & 11.17 & 20.0 & 100 \\
\hline
\end{tabular}

Table 6

Correlations between health literacy level NVS) and the domains in the instrument of quality life assessment (WHOQOL-bref)

\begin{tabular}{|c|c|c|c|c|c|}
\hline & D1. & D2. & D3. & D4. & General \\
\hline D1 Physical & - & & & & \\
\hline D2 Psychological & $0.64^{*}$ & - & & & \\
\hline D3 Social Relations & $0.32 *$ & $0.44 *$ & - & & \\
\hline D4 Environment & $0.61 *$ & $0.69 *$ & $0.45^{*}$ & & \\
\hline General & $0.66^{*}$ & $0.67 *$ & $0.40^{*}$ & $0.65^{*}$ & - \\
\hline
\end{tabular}




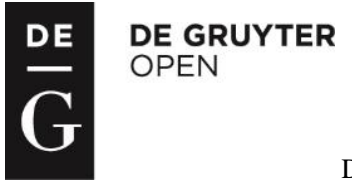

DOI: 10.1515/arhss-2016-0003

Applied Research In Health And Social Sciences: Interface And Interaction, Vol. 13, No. 1, 2016

In a later stage, we analysed the associations between health literacy and quality of life. As can be seen from Table 6 , the associations found are positive and weak, indicating that the higher the perception of quality of life in the different domains, the higher the results in the health literacy test. Once that, as we have seen, age associates to the levels of health literacy, as well as to one of the quality of life domains, specifically, to the physical domain, $r=-.19$, we have repeated the correlation analyses, controlling age. It is noted that the associations are maintained as reported in Table 6.

\section{Discussion}

As to the degree of health literacy, it was confirmed, similarly to other international studies previously referenced (e. g., Speros, 2005; Sudore et al., 2006; Wagner et al., 2007; Manafo \& Wong, 2012; Reisi et al., 2014; Liu et al., 2015) that the health literacy level of the participants is low. These data show the urging need for the development of practices that promote health literacy and reduce the adverse effects of illiteracy in this domain. The analyses conducted indicate a notable effect in some demographic variables in the average values obtained in the health literacy test, specifically, gender, age, academic qualifications and marital status.

Concerning gender, it turns out that the male gender participants obtained higher average scores than the feminine gender participants. However, these differences disappear when the subjects with complete failure in the test were excluded. In the international studies developed there is no concordance, as referred, in the obtained results in this variable. In those in which men presented higher health literacy, the authors associated it to higher scholarship of male gender (e. g., JovicVranes et al., 2009) and lower in feminine gender (e. g., Reisi et al., 2014), similar situation to this study's reality. As to age, it was noted that the levels of literacy tend to be lower as it progresses, which is similar to the results obtained in other international researches (e. g., Baker et al., 2000; Bennett et al., 2009).

As to academic qualifications, it seems to be the variable that presents a more determinant role in the average levels of health literacy. The Mann-Whitney analyses have allowed to verify that the subjects with 1st cycle of Basic Education presented lower results than every other group. In the same way, the subjects with the 2nd or 3rd cycles of Basic Education presented lower results than the groups of subjects with secondary school and higher education; there were, however, no differences in the average scores obtained by the subjects of these two levels of education. These results match the ones obtained in other international researches (e. g., Baker et al., 2000; Bennett et al., 2009), the bibliography used. Being the education level one of the factors that most contribute to health literacy, many investigators/professionals (e. g., Wallace, 2004) stand up for the development of educational health interventions. However, it would be wrong to confine those interventions to the teachinglearning process of reading, writing and numeracy, once the concept of health literacy is not solely 


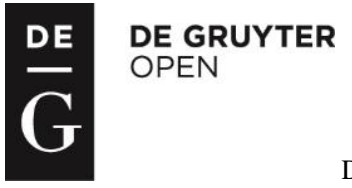

DOI: 10.1515/arhss-2016-0003

Applied Research In Health And Social Sciences: Interface And Interaction, Vol. 13, No. 1, 2016

connected with the increase of health knowledge, but focuses mostly on the development of personal skills likely to motivate the elderly to obtain, understand, critically analyse and use, in everyday life, the information and the services available in the health scope, with a view to amend less healthy practices and to adopt healthy behaviours. Health education is thus "educational, relational and progressive process", that values experience, the life pathway and context, transforming the person into a critical being and an agent for change of his/her own reality, thus becoming the protagonist of his/her life (Hammerschmidt \& Lenardt, 2010, p. 364).

Concerning marital status, it has been noted that, similarly to Reisi et al. (2014), married people tend to obtain higher average scores of health literacy compared to widowers, regardless of age. We put as an explanatory hypothesis for these results the possibility that the conjugal context may favour information exchange on health and disease, a more reflected decision-making, and mutual care, in health and in sickness.

Regarding the existence of disease, it was noted that the participants who claimed, regardless of age, having some sort of disease, obtained lower average scores at literacy level. These results are in concordance with the ones obtained in international studies (e.g., Kim, 2009; Wolf et al., 2005). These results are therefore worrying once the people who could benefit the most from health care services and from the possible protector effect of health literacy are the ones who present a lower degree of health literacy.

Regarding the association between health literacy and quality of life, it indicates that the higher the perception of quality of life in its different domains, by the subjects, the higher the results in the test of health literacy, regardless of age. Elderly who have a higher degree of health literacy have a more favourable perception of their own global well-being, whether at the level of health, life satisfaction and psychological well-being, whether at the level of satisfaction with the social and physical environment in which they are placed. We sought out to confront the obtained results, however, we found no evidence of any studies that assessed these two dimensions in the elderly population. Yet, we found, a few studies regarding the association of these two dimensions in other populations. For example, the research conducted by Husson et al. (2015) has observed that low health literacy is linked to adverse health behaviours and to a worse quality of life among the surviving from colorectal carcinoma. As to the study of Wallace et al (2008), involving subjects that attend a familiar medicine clinic in a university residence, concluded that there was a significant correlation between the health literacy skills of the patients and the self-claimed general health conditions. In other words, patients with limited health literacy skills had a higher average number of days in which they were physically ill and with limited activity compared to patients with proper health literacy skills. The authors conclude that health alphabetization of the patients is associated to several components of life quality related to health. 


\section{Conclusion}

Applied Research In Health And Social Sciences: Interface And Interaction, Vol. 13, No. 1, 2016

In the path of the obtained results, in this and other studies, is the urge for interventions directed to the elderly aiming to improve their quality of life are urgent. The need to boost health literacy among the elderly and among the most vulnerable groups, in particular, is essential so that the elderly can assume himself as an active element, committed and responsible for his health / disease. In this process it is essential that the policy makers, the organizations and the professionals take responsibility for the development of educational interventions promoting health literacy.

As clues for further research, the replication of this study will be needed but with larger samples, at a national level and/or with specific problems/situations in order to contribute to the knowledge of reality in discussion in Portugal. Lastly, due to the fact that international studies on the relation between health literacy and quality of life are scarce, and even inexistent concerning the elderly population, we believe this is an area, which needs urgently to be investigated.

\section{References}

Baker, D., Gazmararian, J., Sudano J., \& Patterson, M. (2000). The association between age and health literacy among elderly persons. The Journals of Gerontology, Series B: Psychological Sciences and Social Sciences, 55(6), 368-374.

Baker, D., Parker, R., Williams, M., Pitkin, K., Parikh, N., Coates, W., \& Imara, M. (1996). The health care experience of patients with low literacy. Archives of Family Medicine, 5(6), 329-334.

Barrett, S., \& Puryear, J. (2006). Health literacy: improving quality of care in primary care settings. Journal of Health Care Poor Underserved, 17, 690-697.

Bennett, I., Chen, J., Soroui, J., \& White, S. (2009). The contribution of health literacy to disparities in self-rated health status and preventive health behaviours in older adults. Annals of Family Medicine, 7(3), 204-211.

Carvalho, P., \& Dias, O. (2011). Adaptação dos idosos institucionalizados. Millenium, 40, 161-184.

Cho, Y., Lee, S., Arozullah, A., \& Crittenden, K. (2008). Effects of health literacy on health status and health service utilization amongst the elderly. Society Science Medical, 66, 1809-1816.

Davis, T., Wolf, M., Bass, P., Middlebrooks, M., Kennen, E., Baker, D. (2006). Low literacy impairs comprehension of prescription drug warning labels. Journal of General Internal Medicine, 21, 847-851.

Direcção-Geral da Saúde (2004). Programa nacional para a saúde das pessoas idosas. Circular normativa, n. ${ }^{\circ} 13 / \mathrm{DGCG}$.

Hammerschmidt, K., \& Lenardt, M. (2010). Tecnologia educacional inovadora paraoempoderamento junto a idosos com Diabetes Mellitus. Texto \& Contexto Enfermagem, Florianópolis, 19(2), 358-365.

Husson, O., Mols, F., Fransen, M., Poll-Franse, L., \& Ezendam, N. (2015). Low subjective health literacy is associated with adverse health behaviours and worse health-related quality of life among colorectal cancer survivors: results from the profiles registry. Psycho-Oncology, 24(4), 478-486.

Jovic-Vranes, A., Bjegovic-Mikanovic, V., \& Marinkovic J. (2009). Functional health literacy among primary health-care patients: data from the Belgrade pilot study. Journal of Public Health, 31(4), 490-495. 
Kim, S. (2009). Health literacy and functional health status in Korean older adults. Journal of Clinical Nursing, $18,2337-2343$.

Lee, S., Tsai, T., Tsai, Y., \& Kuo, K. (2010). Health literacy, health status, and healthcare utilization of taiwanese adults: Results from a national survey. BMC Public Health, 10, 614.

Liu, Y., Liu, L., Li, Y., \& Chen, Y. (2015). Relationship between health literacy, health-related behaviours and health status: A survey of elderly Chinese. International Journal of Environmental Research and Public Health, 12, 9714-9725.

Luís, L. (2010). Literacia em saúde e alimentação saudável: os novos produtos e a escolha de alimentos (Tese de Doutoramento não publicada). Universidade Nova de Lisboa, Lisboa, Portugal.

Manafo, E., \& Wong, S. (2012). Health literacy programs for older adults: a systematic literature review. Health Education Research, 27(6), 947-960.

Nutbeam, D. (2000). Health literacy as a public health goal: a challenge for contemporary health education and communication strategies into the 21st century. Health Promotion InternaTional, 5(3), 259-267.

Osborn, C., Paasche-Orlow, M., Bailey, S., \& Wolf, M. (2011). The mechanisms linking health literacy to behaviour and health status. American Journal of Health Behavior, 35 (1), 118-128.

Rosa, M. (2012). O envelhecimento da sociedade portuguesa. Lisboa: FFMS.

Reisi, M., Javadzade, S., Heydarabadi, A., Mostafavi, F., Tavassoli, E., \& Sharifirad, G. (2014). The relationship between functional health literacy and health promoting behaviours among older adults, Journal of Education and Health Promotion, 29(3): 119.

Santos, O. (2010). O papel da literacia em saúde: capacitando a pessoa com excesso de peso para o controlo e redução da carga ponderal. Endocrinologia, Diabetes \& Obesidade, 4(3), 127-134.

Serrão, C., Veiga, S., Vieira, I., Pereira, V., Cadima, J., Ralha, S., Fonseca, P., \& Marques, A. (2014a). Literacia em saúde: um desafio na e para a terceira idade - e-book. Santa Maria da Feira: Rainho \& Neves.

Serrão, C., Veiga, S., Vieira, I., Almeida, V., Ribeiro, S., Santos, D., Cadima, J., Ralha, S., Fonseca, P., \& Marques, A. (2014b). Literacia em Saúde: um desafio na e para a terceira idade - Manual de Boas Práticas. Maia: Tipografia Lessa-Florentino Martins Lessa \& Filho.

Serrão, C., Veiga, S., \& Vieira, I. (2015). Literacia em saúde: resultados obtidos a partir de uma amostra de pessoas idosas portuguesas. Revista Portuguesa de Enfermagem de Saúde Mental, Especial nº 2, 33-38.

Speros, C. (2005). Health literacy: concept analysis. Journal of Advanced Nursing, 50(6), 633-640.

Sudore, R. L., Mehta, K.M., Simonsick, E.M., Harris, T.B., Newman, A.B., Satterfield, S., \& Yaffe, K. (2006). Limited literacy in older people and disparities in health and healthcare access. Journal of the American Geriatrics Society, 54(5), 770-776.

Toçi, E., Burazeri, G., Sorensen, Jerliu, N., Ramadani, N., Roshi, E., \& Brand, H. (2013). Health literacy and socioeconomic characteristics among older people in transitional Kosovo. British Journal of Medicine \& Medical Research, 3(4), 1646-1658.

Wallace, L. (2004). The impact of limited literacy on health promotion in the elderly. Californian Journal of Health Promotion, 2(3), 1-4. 


\section{DOI: 10.1515/arhss-2016-0003}

Applied Research In Health And Social Sciences: Interface And Interaction, Vol. 13, No. 1, 2016

Wagner, C., Knight, K., Steptoe, A., \& Wardle, J. (2007). Functional health literacy and health-promoting behaviour in a national sample of British adults. Journal of Epidemiology \& Community Health, 6, 10861090.

Wallace, L., Rogers, E., \& Weiss, B. (2008). Relationship between health literacy and health-related quality of life among Tennesseans. Journal of the Tennessee Medical Association, 101(5), 35-39.

Weiss, B. D., Mays, M. Z., Martz, W., Castro, K. M., DeWalt, D. A, Pignone, M. P., \& Mockbee, J. (2005). Quick assessment of literacy in primary care: the newest vital sign. Annals of Family Medicine, 3(6), 514522.

Weiss, B., \& Palmer, R. (2004). Relationship between health care costs and very low literacy skills in a medically needy and indigent medicaid population. The Journal of the American Board of Family Medicine, 17(1), 44-47.

Wolf, M., Gazmararian, J., \& Baker, D. (2005). Health literacy and functional health status among older adults. Archives of Internal Medicine, 165, 1946-1952.

World Health Organization (1997). WHOQOL - Measuring Quality of Life. Geneva: WHO.

World Health Organization (1998). Health Promotion Glossary. Geneva: WHO.

World Health Organization (2002). Active Ageing: A Policy Framework. Geneva: WHO. 